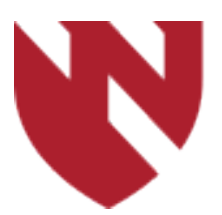

October 2021

\title{
Retro Pharyngeal Abscess and Pott's Disease Due to Tuberculosis: A Case Report
}

\author{
Bailey N. Hassman \\ University of Nebraska Medical Center \\ Steven Curry \\ University of Nebraska Medical Center \\ Jonathan $\mathrm{H}$. Ryder \\ University of Nebraska Medical Center \\ Angela L. Hewlett \\ University of Nebraska Medical Center \\ Jayme Dowdall \\ University of Nebraska Medical Center
}

Tell us how you used this information in this short survey.

Follow this and additional works at: https://digitalcommons.unmc.edu/gmerj

Part of the Higher Education Commons, and the Medicine and Health Sciences Commons

\section{Recommended Citation}

Hassman, B. N., Curry, S., Ryder, J. H., Hewlett, A. L., , Dowdall, J. Retro Pharyngeal Abscess and Pott's Disease Due to Tuberculosis: A Case Report. Graduate Medical Education Research Journal. 2021 Oct 04; 3(1). https://digitalcommons.unmc.edu/gmerj/vol3/iss1/24 
Retro Pharyngeal Abscess and Pott's Disease Due to Tuberculosis: A Case Report

Creative Commons License

(c) (i) (9)

This work is licensed under a Creative Commons Attribution-Noncommercial-No Derivative Works 4.0 License. 


\section{Retro Pharyngeal Abscess and Pott's Disease Due to Tuberculosis: A Case Report}

Bailey N. Hassman', Steven D. Curry ${ }^{2}$, Jonathan H. Ryder ${ }^{3}$, Angela L. Hewlett ${ }^{3}$, Jayme R. Dowdall ${ }^{2}$

${ }^{1}$ University of Nebraska Medical Center, College of Medicine

'University of Nebraska Medical Center, College of Medicine, Department of Otolaryngology - Head and Neck Surgery

${ }^{3}$ University of Nebraska Medical Center, College of Medicine, Department of Internal Medicine, Division of Infectious Diseases

Mentor: Jayme R. Dowdall

Program: Otolaryngology - Head and Neck Surgery

Type: Case Report

Background: Extrapulmonary mycobacterial infection can lead to vertebral spondylitis and osteomyelitis (Pott's disease).

Retropharyngeal abscess with concurrent spinal osteomyelitis is a rare presentation of tuberculosis in the U.S. Chart review on a patient was completed, and the relevant published literature was reviewed.

Case: A previously healthy 34 -year-old male originally from Sudan presented to an outside hospital with a 2-month history of neck pain, sore throat, odynophagia, fevers, and chills. MRI showed a retropharyngeal abscess and suspected cervical spine osteomyelitis. Acid-fast bacillus (AFB) smear was positive from a neck drain specimen, but sputum was negative. Chest imaging did not show clear signs of pulmonary tuberculosis, and the patient did not have other findings consistent with pulmonary disease. He was treated with rifampin, isoniazid, pyrazinamide, and ethambutol (RIPE) along with moxifloxacin and linezolid due to concern for possible multidrug resistant $\mathrm{TB}$ and transferred to UNMC for further care. Culture isolated Mycobacterium tuberculosis. CT neck showed vertebral tuberculous osteomyelitis (Pott's disease) of C1-C3 with a multiloculated retropharyngeal and prevertebral abscess (Fig. 1 on next page). The patient was taken to the OR for posterior spinal fusion from occiput to $\mathrm{C} 4$ and transoral incision and drainage of the abscess. The post-operative course was uneventful, and moxifloxacin and linezolid were discontinued based on susceptibility testing. At follow-up the patient's symptoms had resolved. Patient consent was obtained to utilize this case for educational purposes.

Conclusions: This report presents the multidisciplinary treatment of this patient requiring infection control measures and antibiotic therapy by infectious disease, posterior spine fusion by orthopedic surgery, and retropharyngeal abscess drainage by otolaryngology.

https://doi.org/10.32873/unmc.dc.gmerj.3.1.044

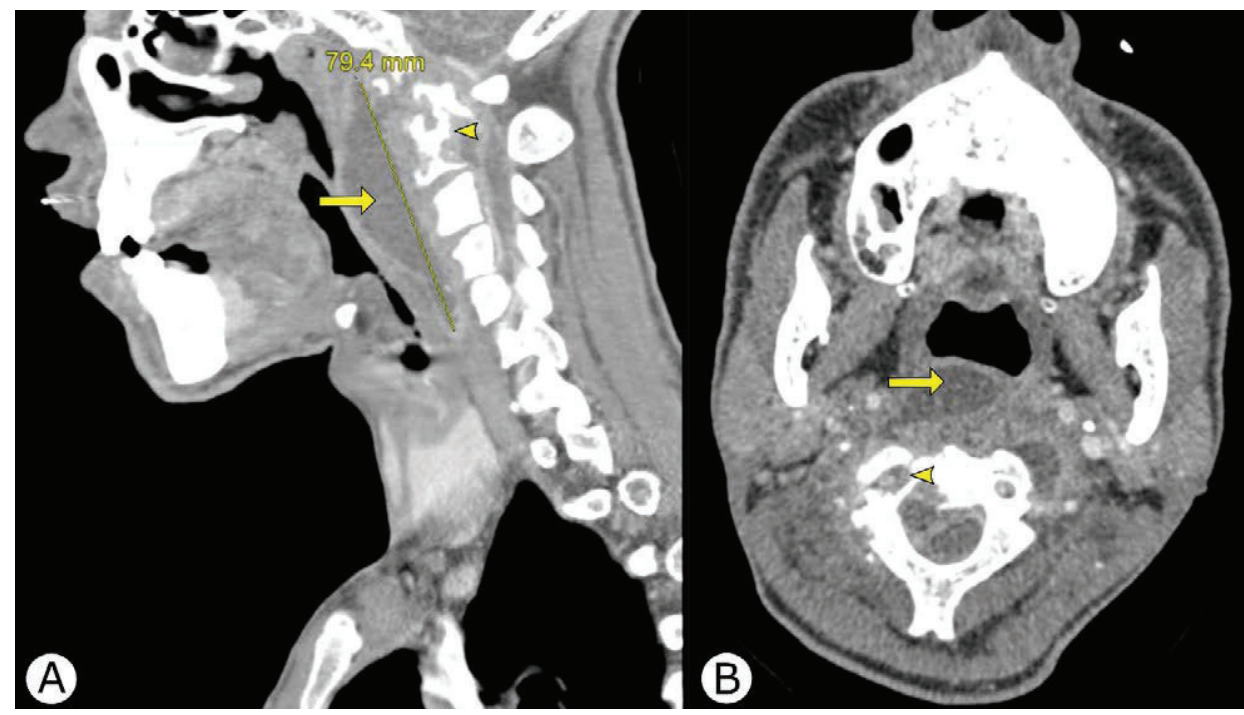

Figure 1. CT soft tissue neck with contrast in soft tissue window. Sagittal (A) and axial (B) images show retropharyngeal abscess (arrow) and cervical osteolytic destruction (arrowhead).

\section{Just When You Thought You Broke Your Foot}

Ben Noble ${ }^{1}$, T. Jason Meredith 1

${ }^{1}$ University of Nebraska Medical Center, College of Medicine, Department of Family Medicine

\section{Mentor: T. Jason Meredith \\ Program: Family Medicine}

Type: Case Report

Background: This case report demonstrates a common presentation for an atypical cause of foot pain.

Case: A 17 y/o female football player with right foot pain presented to clinic for a second opinion. Three weeks prior, she everted her ankle at practice, experiencing immediate pain, swelling, and ecchymosis in her foot. An outside provider obtained plain films and diagnosed the patient with a "foot fracture." She was made non-weight bearing for three weeks, then released to return to play without repeat imaging. The mother of the patient and her school's athletic trainer were concerned with plan and desired a second opinion.

At our initial visit, patient was non-weight bearing secondary to pain. She rated her pain at $6 / 10$. Her past medical history was notable for bilateral pes planus and medial tibial stress syndrome. Her exam was remarkable for tenderness over her navicular and distal tibialis posterior tendon. Plain films were obtained that demonstrated no occult navicular fracture, but an accessory navicular bone was noted. Patient was diagnosed with a symptomatic accessory navicular bone.

Patient was made non-weight bearing for two weeks then transitioned to weight bearing as tolerated in lace-up ankle brace with initiation of rehab with her school's athletic trainer.
At 4-week follow-up, she was pain free and allowed to return to full participation.

Conclusion: Accessory navicular bones often present in young patients with pes planus and lie along the superior medial border of the navicular bone and in close proximity to the tibialis posterior tendon. Painful accessory naviculars often respond well to conservative treatment, including non-weight bearing and physical therapy. If conservative management fails, referral to orthopedic surgery may be necessary for surgical removal of the accessory navicular bone.

https://doi.org/10.32873/unmc.dc.gmerj.3.1.045 